\title{
COMPARATIVE ASSESSMENT OF IN VITRO ANTIMICROBIAL ACTIVITY OF CURCUMA CAESIA ROXB. AND CURCUMA AMADA ROXB
}

\author{
RANDEEP KAUR ${ }^{1}$, BARINDERJIT KAUR ${ }^{2}$, ASHISH SUTTEE ${ }^{1}$, VANDNA KALSI $^{1 *}$ \\ ${ }^{1}$ Department of Pharmacognosy, School of Pharmaceutical Sciences, Lovely Professional University, Phagwara, Punjab, India. \\ ${ }^{2}$ Department of Pharmacology, School of Pharmaceutical Sciences, Lovely Professional University, Phagwara, Punjab, India. \\ Email: vandana.kalsi@lpu.co.in
}

Received: 05 April 2018, Revised and Accepted: 09 July 2018

ABSTRACT

Objective: The aim of the present study was to compare the in vitro antimicrobial activity of Curcuma caesia Roxb. and Curcuma amada Roxb. family Zingiberaceae. Both plants have been used traditionally for curing a number of diseases and ailments. The plants have been specifically used in skin problems and inflammatory conditions.

Methods: Each plant material was extracted with dichloromethane (DCM) and ethanol. All extracts were subjected to preliminary phytochemical screening. The antibacterial activity of the extracts was tested against two Gram-positive (Staphylococcus aureus, Streptococcus pyogenes), and two Gram-negative bacteria (Escherichia coli, Pseudomonas aeruginosa) using the cup-plate method. The standard drug used was ofloxacin (0.2 ml) at a concentration of $5 \mathrm{mg} / \mathrm{ml}$. The antifungal activity was tested against Aspergillus fumigatus, and Candida albicans using the cup-plate method and clotrimazole $(10 \mathrm{mg} / \mathrm{ml})$ was taken as standard reference.

Results: Phytochemical screening performed on the extracts has shown the presence of various constituents such as glycosides, carbohydrates, saponins, phytosterols, resins, flavonoids, and diterpenoids. On comparing both species, C. amada was found to be stronger growth inhibitor against both Gram-positive and Gram-negative strains. C. caesia ethanol extract at a dose of $200 \mathrm{mg} / \mathrm{ml}$ was most effective and $C$. amada DCM extract $100 \mathrm{mg} / \mathrm{ml}$ was least effective in case of antifungal activity against $C$. albicans. In case of $A$. fumigatus, C. caesia DCM extract $100 \mathrm{mg} / \mathrm{ml}$ was least effective and $C$. caesia ethanol extract $200 \mathrm{mg} / \mathrm{ml}$ was most effective.

Conclusion: The present study provides the information on phytochemical screening and antimicrobial activities of extracts prepared from two plants of family Zingiberaceae, i.e., C. caesia Roxb. and C. amada Roxb.

Keywords: Curcuma caesia, Curcuma amada, Zingiberaceae, Phytochemical screening

(C) 2018 The Authors. Published by Innovare Academic Sciences Pvt Ltd. This is an open access article under the CC BY license (http://creativecommons. org/licenses/by/4. 0/) DOI: http://dx.doi.org/10.22159/ajpcr.2018.v11s2.28591

\section{INTRODUCTION}

Plants have been regarded as living biochemical factories that provide a vast variety of chemical substances displaying some biological activities. About 35000 plant species are used throughout the world for one or other medicinal purpose. Researchers from various fields have screened only a small fraction of the plants for their phytochemical and pharmacological potentials [1].

Family Zingiberaceae is a large family with 46 to 52 genera and more than a thousand species. Plants in this family are found in the tropics of Africa, Asia, and America, with the greatest number in Southeast Asia. These are small to large perennial plants with creeping horizontal or tuberous rhizomes [2]. Curcuma is a genus of about 80 species in the family Zingiberaceae, and about 40 of them are indigenous to India [3].

Curcuma caesia Roxb. is commonly known as Kali haldi (Fig. 1). It is a perennial herb, and in India, it grows in West Bengal, Madhya Pradesh, Orissa, Bihar, and Uttar Pradesh and is used by the tribal people to cure various ailments [4]. The name "black turmeric" holds due to the presence of cells related to black color in the rhizome. The plant is claimed to be useful in treating piles, leprosy, bronchitis, asthma, cancer, and epilepsy. A paste of rhizomes is applied externally for curing wounds, pimples, and allergies [5].

Curcuma amada Roxb. is commonly known as Amba haldi or Mango ginger. Is a unique spice having morphological resemblance with ginger
(Zingiber officinale) but has raw mango flavor (Fig. 2). It is widely distributed in the tropics from Asia to Africa and Australia [6]. Mango ginger rhizome has been reputed as an appetizer, alexteric, antipyretic, aphrodisiac, and a laxative. It is also used in itching, skin diseases, bronchitis, asthma, and inflammation due to injuries [5].

\section{METHODS}

\section{Plant collection}

Dried rhizomes of $C$. caesia and C. amada were purchased from local market of Amritsar. The plant materials were authenticated by Dr. Shiddamallayya at Regional Research Institute (Ay), Bangalore.

\section{Preparation of plant extracts}

The dried rhizomes (50 g) of both species were coarsely powdered and subjected to successive solvent extraction using Soxhlet Assembly. The extraction was accomplished with different solvents in their increasing order of polarity, namely petroleum ether, dichloromethane (DCM), ethanol, and distilled water. The marc was dried before the extraction with the next solvent. These extracts were evaporated to dryness by rotary vacuum evaporator [7].

\section{Preliminary phytochemical investigation}

The phytochemical investigation covers the identification of crude drug with respect to their phytochemical constituents. The extracts were subjected to preliminary phytochemical screening according to the standard procedures [8]. 


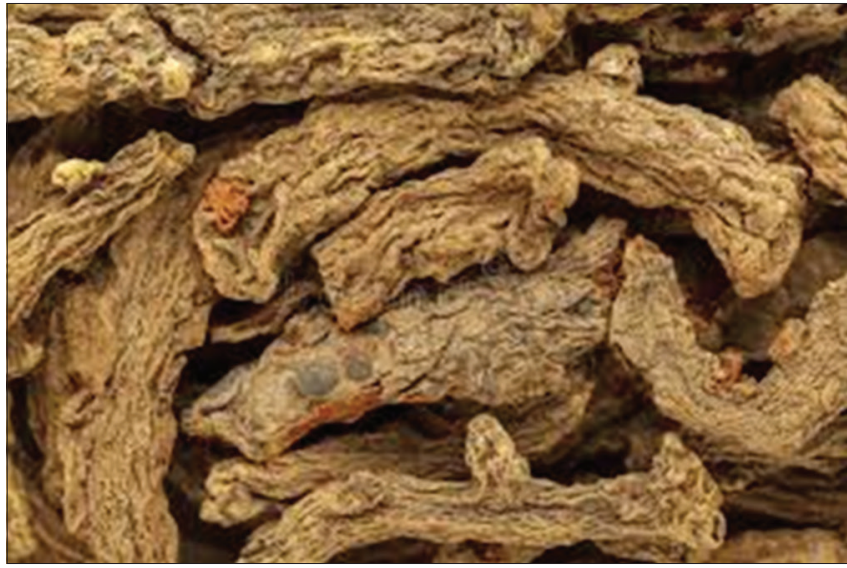

Fig. 1: Rhizomes of Curcuma caesia

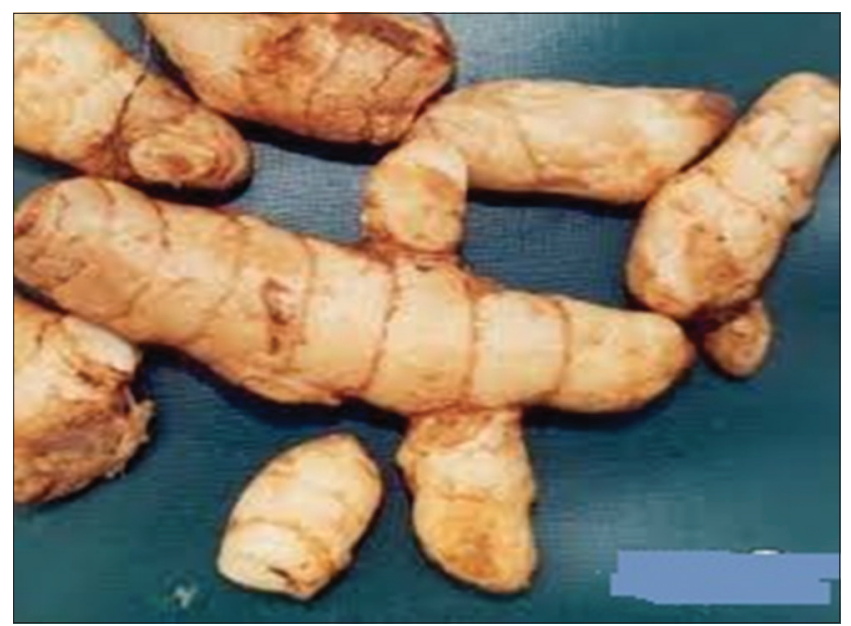

Fig. 2: Rhizomes of Curcuma amada

\section{Antimicrobial activity}

Antibacterial activity was tested against two Gram-positive (Staphylococcus aureus and Streptococcus pyogenes) and two Gramnegative bacteria (Pseudomonas aeruginosa and Escherichia coli). The antifungal activity was tested against Aspergillus fumigatus and Candida albicans. The above-mentioned bacterial and fungal strains were revived by plating on nutrient agar and Sabouraud dextrose agar, respectively. Isolated colonies were selected after overnight incubation at $37^{\circ} \mathrm{C}$. The cup-plate method was used to check the antibacterial and antifungal activities. Ofloxacin $(0.2 \mathrm{ml})$ at a concentration of $5 \mathrm{mg} / \mathrm{ml}$ was taken as a standard reference for antibacterial activity, and clotrimazole $(10 \mathrm{mg} / \mathrm{ml})$ was taken as a standard reference for antifungal activity [9].

\section{Determination of antibacterial activity}

The suspension of bacteria was prepared as per McFarland standard. An inoculum was prepared by suspending a single isolated colony in about $5 \mathrm{ml}$ of normal saline. This was mixed slowly to achieve a smooth suspension. Boring of wells was done on the medium using a sterile borer. A fixed amount of inoculum $(0.25 \mathrm{ml})$ was added to $30 \mathrm{ml}$ of sterile solidified nutrient agar medium in Petri dishes. Different extracts $(0.1 \mathrm{ml})$ were poured in three concentrations $(100,150$, and $200 \mathrm{mg} / \mathrm{ml}$ ) in different wells marked as 1,2 , and 3 of the solidified seeded nutrient agar layer in Petri dishes. The Petri dishes were incubated at $37^{\circ} \mathrm{C}$ for $24 \mathrm{~h}$, and zones of inhibition were observed and measured using a scale. The values of zones of inhibition were recorded in triplicate, and the results were reported in mean $( \pm$ standard error of the mean [SEM]) [9].
Determination of antifungal activity

The suspension of fungus was prepared as per McFarland standard. An inoculum was prepared by suspending a single isolated colony in about $5 \mathrm{ml}$ of normal saline. This was mixed slowly to achieve a smooth suspension [10]. Later, one drop of tween 20 was added for filamentous fungi, and the mold was broken by shaking. Four bores per plate were made using sterile cork borer. The surface of Sabouraud's agar medium plate was streaked with the help of spreader in all the directions for uniform distribution of fungal strain. Different extracts were poured in three concentrations $(100$, 150 , and $200 \mathrm{mg} / \mathrm{ml}$ ) in different holes marked as 1,2 , and 3 of the solidified seeded nutrient agar layer in Petri dishes. The test solution $(0.1 \mathrm{ml})$ was added to the respective bores. The surface of Sabouraud's agar plate was dried. The above procedure was carried under aseptic conditions. The plates were incubated at $28^{\circ} \mathrm{C}$ for 48 h. Later, the values of zones of inhibition were recorded in triplicate and reported in mean $( \pm$ SEM) [11].

\section{Statistical analysis}

Data have been summarized as the mean \pm standard deviation. A statistical significant test with control was done using one-way ANOVA followed by using Dunnett's test, and $\mathrm{p}<0.01$ was considered statistically significant.

\section{RESULTS AND DISCUSSION}

Medicinal plants are rich sources of antimicrobial agents, which are used medicinally in different countries and are a source of many potent drugs used for traditional medicine. Medicinal plants exhibit antimicrobial activity by different mechanisms. This can be achieved by the inhibition of cell wall synthesis, interference with the permeability of cell membrane, cause membrane disruption, modifying cellular constituents, and cell damage or cell mutation [12]. Most of the solvents such as ethanol, hexane, and methanol, when used for plant extract showed inhibitory effect on Gram-positive and Gram-negative bacteria [13].

The phytochemical screening conducted on the plant extracts revealed the presence of chemical constituents, which are known to exhibit medicinal as well as physiological activities. Both plants showed similar results in phytochemical screening. C. caesia and C. amada extracts were found to contain carbohydrates, saponins, glycosides, phytosterols, resins, and flavonoids. Test for glycosides was positive in all the extracts. The ethanol extract of both plant materials was rich in glycosides and contained most of the other chemical constituents also.

Many plants with high flavonoid and saponins contents have been reported to exhibit potential antimicrobial activity against pathogenic microorganisms [14].

The cup-plate method is one of the official methods in IP, where test samples diffuse from the cup through an agar layer in a Petri dish to such an extent that the growth of microorganisms is restricted to a circular area or confined zone around the cavity containing the solution of an antibiotic substance [15].

The antibacterial activity of two extracts (DCM and Ethanol) of C. caesia and C. amada was studied using the cup-plate method, and the results are shown in Table 1 . The antibacterial activity of $C$. caesia and $C$. amada was performed against two Gram-positive ( $S$. aureus, S. pyogenes) and two Gram-negative bacteria (E. coli, $P$. aeruginosa). In case of antibacterial activity against $S$. aureus, the zone of inhibition was maximum in C. caesia DCM extract $(200 \mathrm{mg} /$ $\mathrm{ml}$ ). Similar inhibition was observed in $C$. caesia ethanol extract (200 mg/ml). C. amada ethanol extract $(100 \mathrm{mg} / \mathrm{ml})$ was least effective. In case of $S$. pyogenes, $C$. amada DCM extract $(200 \mathrm{mg} / \mathrm{ml}$ ) was most effective and C. caesia DCM extract $(100 \mathrm{mg} / \mathrm{ml})$ was least 
Table 1: Effect of Curcuma species on Gram-positive and Gram-negative bacteria

\begin{tabular}{|c|c|c|c|c|c|}
\hline \multirow[t]{3}{*}{ Groups } & \multirow[t]{3}{*}{ Dose mg/ml } & \multicolumn{4}{|c|}{ Zone of inhibition (mm) } \\
\hline & & \multicolumn{2}{|c|}{ Gram-positive bacteria } & \multicolumn{2}{|c|}{ Gram-negative bacteria } \\
\hline & & S. aureus & S. pyogenes & E. coli & P. aeruginosa \\
\hline C. caesia & 100 & $13 \pm 0.57^{* *}$ & $11.66 \pm 0.67^{* *}$ & $12.33 \pm 0.33^{* *}$ & $12 \pm 0.00^{* *}$ \\
\hline DCM & 150 & $17.33 \pm 0.67^{* *}$ & $14 \pm 0.00^{* *}$ & $18.33 \pm 0.33^{* *}$ & $13.66 \pm 0.33^{* *}$ \\
\hline Extract & 200 & $19.66 \pm 0.67^{* *}$ & $16.33 \pm 0.33^{* *}$ & $20 \pm 0.57^{* *}$ & $15.66 \pm 0.33^{* *}$ \\
\hline C. caesia & 100 & $12.66 \pm 0.67^{* *}$ & $13.33 \pm 0.33^{* *}$ & $20.66 \pm 0.33^{* *}$ & $14 \pm 0.00^{* *}$ \\
\hline Extract & 200 & $19 \pm 0.00 * *$ & $16.33 \pm 0.68^{* *}$ & $23.66 \pm 0.33^{* *}$ & $25 \pm 0.00^{* *}$ \\
\hline C. amada & 100 & $12.6 \pm 0.33^{* *}$ & $12.3 \pm 0.33^{* *}$ & $11.33 \pm 0.33^{* *}$ & $10.66 \pm 0.33^{* *}$ \\
\hline DCM & 150 & $14.6 \pm 0.33^{* *}$ & $14.3 \pm 0.33^{* *}$ & $16 \pm 0.57^{* *}$ & $13.33 \pm 0.33^{* *}$ \\
\hline Extract & 200 & $18.6 \pm 0.33^{* *}$ & $19.3 \pm 0.88^{* *}$ & $17.6 \pm 0.33^{* *}$ & $16.3 \pm 0.33^{* *}$ \\
\hline C. amada & 100 & $12 \pm 0.57 * *$ & $13.33 \pm 0.33^{* *}$ & $12.33 \pm 0.33^{* *}$ & $13.33 \pm 0.33^{* *}$ \\
\hline Ethanol & 150 & $13.6 \pm 0.33^{* *}$ & $17.66 \pm 0.33^{* *}$ & $14 \pm 0.57^{* *}$ & $14 \pm 0.57^{* *}$ \\
\hline Extract & 200 & $16.6 \pm 0.33^{* *}$ & $19.33 \pm 0.33^{* *}$ & $17.66 \pm 0.33^{* *}$ & $18.33 \pm 0.33^{* *}$ \\
\hline Standard & 5 & $25.91 \pm 0.95$ & $26.08 \pm 0.63$ & $26.415 \pm 0.77$ & $28.25 \pm 0.32$ \\
\hline
\end{tabular}

Each value represents mean \pm SEM, $n=3$. Statistical significant test with control was done using one-way ANOVA followed by using Dunnet test, ${ }^{* *} \mathrm{p}<0.01$. $S$. aureus: Staphylococcus aureus, S. pyogenes: Streptococcus pyogenes, E. coli: Escherichia coli, P. aeruginosa: Pseudomonas aeruginosa, C. caesia: Curcuma caesia, DCM: Dichloromethane

Table 2: Effect of Curcuma species on fungal strains

\begin{tabular}{llll}
\hline Groups & $\begin{array}{l}\text { Dose } \\
\mathbf{m g} / \mathbf{m l}\end{array}$ & \multicolumn{2}{l}{ Zone of inhibition $(\mathbf{m m})$} \\
\cline { 3 - 4 } & & C. albicans & A. fumigatus \\
\hline C. caesia & 100 & $12.33 \pm 0.333^{* *}$ & $9 \pm 0^{* *}$ \\
DCM & 150 & $14 \pm 0^{* *}$ & $15 \pm 0^{* *}$ \\
Extract & 200 & $16.33 \pm 0.333^{* *}$ & $16 \pm 0^{* *}$ \\
C. caesia & 100 & $16.33 \pm 0.333^{* *}$ & $11.66 \pm 0.333^{* *}$ \\
Ethanol & 150 & $19.33 \pm 0.333^{* *}$ & $20.33 \pm 0.333$ \\
Extract & 200 & $25 \pm 0^{* *}$ & $25.66 \pm 0.333$ \\
C. amada & 100 & $10 \pm 0^{* *}$ & $11.33 \pm 0.333^{* *}$ \\
DCM & 150 & $11 \pm 0^{* *}$ & $14.83 \pm 0.441^{* *}$ \\
Extract & 200 & $13.66 \pm 0.333^{* *}$ & $17.33 \pm 0.333^{* *}$ \\
C. amada & 100 & $12.33 \pm 0.333^{* *}$ & $10 \pm 0 * *$ \\
Ethanol & 150 & $15 \pm 0^{* *}$ & $13.6 \pm 0.333^{* *}$ \\
Extract & 200 & $17 \pm 0^{* *}$ & $15.33 \pm 0.881^{* *}$ \\
Standard & 10 & $21.5 \pm 0.27$ & $24.16 \pm 1.29$ \\
(Clotrimoxazole) & & & \\
\hline
\end{tabular}

Each value represents mean \pm SEM, $n=3$. Statistical significant test with control was done using one-way ANOVA followed by using Dunnet test, $* * \mathrm{p}<0.01$. C. albicans: Candida albicans, A. fumigatus: Aspergillus fumigatus, DCM: Dichloromethane, C. amada: Curcuma amada

effective. In case of antibacterial activity against E. coli, DCM extract of $C$. caesia was more effective than C. amada at all concentrations; whereas, the ethanol extract of $C$. caesia was more effective than C. amada at all concentrations. The activity increases from DCM extract to ethanol extract with increasing dose. Maximum zone of inhibition was shown by C. caesia ethanol extract $(200 \mathrm{mg} / \mathrm{ml})$ which was nearly similar to that of the standard. Similar results were observed in case of $P$. aeruginosa. The activity increases from DCM extract to ethanol extract with increasing dose. On comparing both species, C. amada was found to be stronger growth inhibitor against both Gram-positive and Gram-negative strains.

C. caesia ethanol extract at a dose of $200 \mathrm{mg} / \mathrm{ml}$ was most effective, and C. amada DCM extract $100 \mathrm{mg} / \mathrm{ml}$ was least effective in case of antifungal activity against $C$. albicans (Table 2). Dose-dependent inhibition was observed. The ethanol extract was more effective than DCM extract whereas $C$. caesia showed better antifungal activity when compared to $C$. amada. In case of A. fumigatus, C. caesia DCM extract $100 \mathrm{mg} / \mathrm{ml}$ was least effective and $C$. caesia ethanol extract $200 \mathrm{mg} / \mathrm{ml}$ was most effective. In case of DCM extract, C. amada at a dose of $200 \mathrm{mg} / \mathrm{ml}$ was most effective.

\section{CONCLUSION}

The results of the present investigations suggest that these plant species are important for further investigations on isolation and characterization of the bioactive principles responsible for the antifungal activity. Moreover, these medicinal herbs may afford lead compounds, which could be beneficial for the future drug development. The phytochemical analysis conducted on the plant extracts revealed the presence of various biologically active constituents. The most active extracts can be subjected to the isolation of therapeutic antimicrobial agents to carry further research in this area.

\section{ACKNOWLEDGMENT}

The authors are thankful to Lovely Professional University, Punjab, India, for providing necessary facilities to carry out this work.

\section{REFERENCES}

1. Ambarwati NS, Elya B, Malik A, Hanafi M. Phytochemical and antimicrobial studies on Garcinia lattissima Miq. fruit extract. Asian J Pharm Clin Res 2017;10:230-2.

2. Norajit K, Laohakunjit N, Kerdchoechuen O. Antibacterial effect of five Zingberaceae essential oils. Molecules 2007;12:2047-60.

3. Policegoudra RS, Diwakar S, Aradhya SM. Identification of difurocumenonol, a new antimicrobial compound from Mango ginger (Curcuma amada Roxb.) rhizomes. J Appl Microbiol 2007;102:1594-602.

4. Pandey AK, Chowdhury AR. Volatile constituents of the rhizome oil of Curcuma caesia Roxb. from central India. Flavour Fragr J 2003;18:463-5.

5. Kirtikar KR, Basu BD. Indian Medicinal Plants. $2^{\text {nd }}$ ed. Dehradun, India: Bishen Singh and Mahendrapal Singh Publishers; 1999.

6. Sasikumar B. Genetic resources of Curcuma: Diversity, characterization and utilization. Plant Genet Resour 2005;3:230-51.

7. Johnson M, Kalaiarasi V, Sivaraman A, Janakiraman N, Babu A, Narayani M. Phytochemical and antibacterial studies on Aristolochia tagala Cham. World J Pharm Res 2014;3:2172-8.

8. Harborn JB. Phytochemical Method a Guide to Modern Techniques of Plant Analysis. $3^{\text {rd }}$ ed. London, New York: Chapman and Hall; 2005. p. 41-5, 74-90, 245.

9. Satish S, Mohan DC, Raghavendra MP, Raveesha KA. Antifungal activity of some plant extracts against important seed borne pathogens of Aspergillus sp. J Agric Tech 2007;2:109-19.

10. Hazen KC, Chery MP, Han Y. Potential use of bac T/alert automated blood culture system for antifungal susceptibility testing. J Clin Microbiol 1994;32:848-50.

11. Jagessar RC, Mohameda A, Gomesb G. An evaluation of the antibacterial 
and antifungal activity of leaf extracts of Momordica charantia against Candida albicans, Staphylococcus aureus and Escherichia coli. Nat Sci 2008;6:1-4.

12. Achika JI, Ndukwe GI, Ayo RG. Phytochemical screening and antimicrobial studies of aerial part of Aeschynomene uniflora Mey. Ind Chem 2016;2:113.

13. Rao AS, Shobha KL, Almeida PM, Rai KS. In vitro antimicrobial activity of root extract of Clitoria ternatea. Asian J Pharm Clin Res 2017; 10:52-4

14. Lekshmi NC, Sumi SB, Viveka S, Brindha JR. Antibacterial activity of nanoparticles from Allium sp. J Microbiol Biotechnol Res 2012;2:115-9.

15. Seeley HW, Van Denmark PJ. Microbes in Action: A Laboratory Manual of Microbiology. $2^{\text {nd }}$ ed. Bombay: D B. Taraporewala Sons and Co.; 1975. p. 55-80. 